\title{
Semantic correlation between emojis and feelings' descriptions for Mapping Emotions into the Urban Mobility context
}

\author{
Gabriele Silveira Camara $^{\mathrm{a}}$ *, Silvana Philippi Camboim ${ }^{\mathrm{a}}$, João Vitor Meza Bravo ${ }^{\mathrm{b}}$ \\ ${ }^{a}$ Federal University of Parana, Graduate Program in Geodetic Sciences, camaragabriele@gmail.com, \\ silvanacamboim@gmail.com \\ ${ }^{b}$ Federal University of Uberlandia, Institute of Geography, Graduate Program in Geography and \\ Graduate Program in Agriculture and Geospatial Information, jvmbravo@gmail.com \\ * Corresponding author
}

Keywords: Emotional Maps, Emojis, Urban Mobility

\begin{abstract}
:
In this research, we characterised and validated a set of emojis for collecting and representing on maps the people's emotional response into the urban mobility context. This study is part of research in progress that aims to create a framework that allows mapping people's feelings about urban environments while moving through different transport modes (Camara, Camboim and Bravo, 2021). Here we assume that emojis are graphic symbols that evoke a natural emotional association with data-space, such as the Chernoff Faces from Eugine Turner in 1977 (Turner, 1977). Thus, here we argued that emojis are modern language tools that become alternatives to represent people's emotional response on maps (Churches et al., 2014).
\end{abstract}

Several pieces of research on the field of Emotional Cartography have been developed to collect and represent the individuals' intangible emotional bonds with the geographic space (Nold, 2009; Gartner, 2012; Griffin and McQuoid, 2012). Applications in this area of Cartography have been widely explored in several urban planning contexts, especially on developing policies based on the citizens' needs, including those on urban mobility. Here we underline researches on the improvements of pedestrians' experiences (Klettner et al., 2013), the walkability (Panek, 2018), the improvements of cyclists' experience (Zeile et al., 2015), and quality of life and well-being in cities (Mackerron and Mourato, 2013).

Thus, in the first study of our research project, we have developed a framework to collect and represent emotional data during an intermodal challenge in the city of Curitiba, Brazil (Camara, Camboim, and Bravo, 2021). Participants were encouraged to record which emoji represented their emotions about the city while travelling on different routes, using different transport modes. The method we developed has enabled us to visualise the individuals' emotional responses to the urban environment through the emojis and their geographic positions on the map (Camara, Camboim, and Bravo, 2021). Although the results also enabled us to establish a relationship between positive and negative emotions with the urban space. However, we have identified the need to comprehend the semantics of the emojis used in this experiment, considering the context of urban mobility and individuals' different and heterogeneous realities. Then, we have designed an experiment to fill this gap, which is the focus of what we report here. The emojis used are from Emojitwo open source set, available under a CC-BY 4.0 license (https://emojitwo.github.io/ ).

The experiment was carried online, where we interviewed 219 individuals, in Portuguese. The main goal was to research the completeness of the list of emotions proposed in the first study and analyse the correlation emojis/emotions with participants' profiles regarding gender, type of transport, and age. Therefore, in the first part of the interview, we have collected information about the individuals' profiles. Then, in the second part, we have asked participants to describe a set of emojis, each with a word that expresses the emotion within the urban mobility context. The evaluation of the individuals' understanding of the emojis meaning was made by summing the percentages of answers considered correct or correct associative. The total number obtained was then validated using two methods of determining the acceptance threshold. The first method we have chosen was proposed by Clarke (1989), which considers as effective symbols those who achieve 50\% (or more) of correct answers. The second method was proposed by Formiga (2012), who believes that adequate symbols achieve at least $66 \%$ correct answers. In the third moment, we have asked the individuals to classify emojis' valencies according to positive, neutral, and negative categories of feelings (Novak, 2015). After that, we have called the participants to associate the emojis with five emotions universally expressed and recognized, considered as basic (Ekman, 1994; Panksepp, 2005; Barrett et al, 2007), despite the basic emotions are still being discussed (LeDoux, 2012). In the last stage of the interview, we measured the frequency of emotions related to the urban mobility context to establish the most representative emojis for that purpose.

Participants belonged to different age groups, from the age of 18 to over 60 . The age group with the most participation was 25 to 29 years old, comprising $22.8 \%$. Regarding gender responses, $67.5 \%$ identified as "female", $31.5 \%$ as "male", 
and $1 \%$ as other gender identities. The participants were geographically distributed all over the Brazilian territory, mainly in the south, southeast, and northeast regions. One of the participants was born in German, and also there were participants from Portugal and Chile. Finally, more than half of the participants (56.6\%) said that they always use emojis to communicate on social media, and only $1.8 \%$ reported that they have never used emojis for communication purposes. Participants were also asked to tell us which transport modes they generally use in their daily lives. As a result, the transport mode car has been chosen more times than the other options, and the motorcycle was ranked as the last one.

Here, we have found that the participants did not comprehend emojis referring to "envy $\because$ " and "impatience $\because$ because both have not been validated at the thresholds. In contrast, the emojis-emotions association of "pity * $\rightarrow$ ",

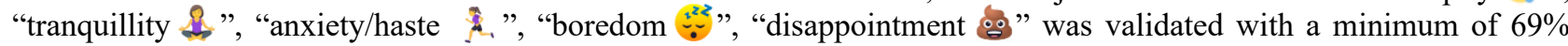
effectiveness and a maximum of $98 \%$. Concerning the classification of emotions represented by the emojis - positive, negative, and neutral - all emojis initially considered positive continued with this classification. On the other hand, there was a change in the emojis classified as negative and neutral since the first mapping test considered these two extracts together. Regarding the emojis that represented basic emotions such as "joy $\because$ ", "sadness $\because-$, "anger "disgust $\because$ ", all were related to emotions by most participants. The emotion with the highest number of correct answers was "anger ", with $96.3 \%$ correct answers, and the next one was "joy $\because$ ", with $61.2 \%$. Finally, we have defined a list with 20 associations emojis-emotions, which were validated by the thresholds. The symbols we defined differ only in two classes compared to those from the first research we have made (Camara, Camboim and Bravo, 2021). Specifically, the first symbol $\because$ was added to characterise "fear", "worry", "tension", and "nervousness". The second one

Additionally, the emotions of "sadness" and "pity" were represented by a unique emoji the emotions of "animation" and "strength" with symbol because they present many similarities in interpretation. An emoji $\bigcirc$ tested with more correct answers replaced the original "envy" one. Figure 1 presents the final list of emojis obtained through this research and their respective valences.

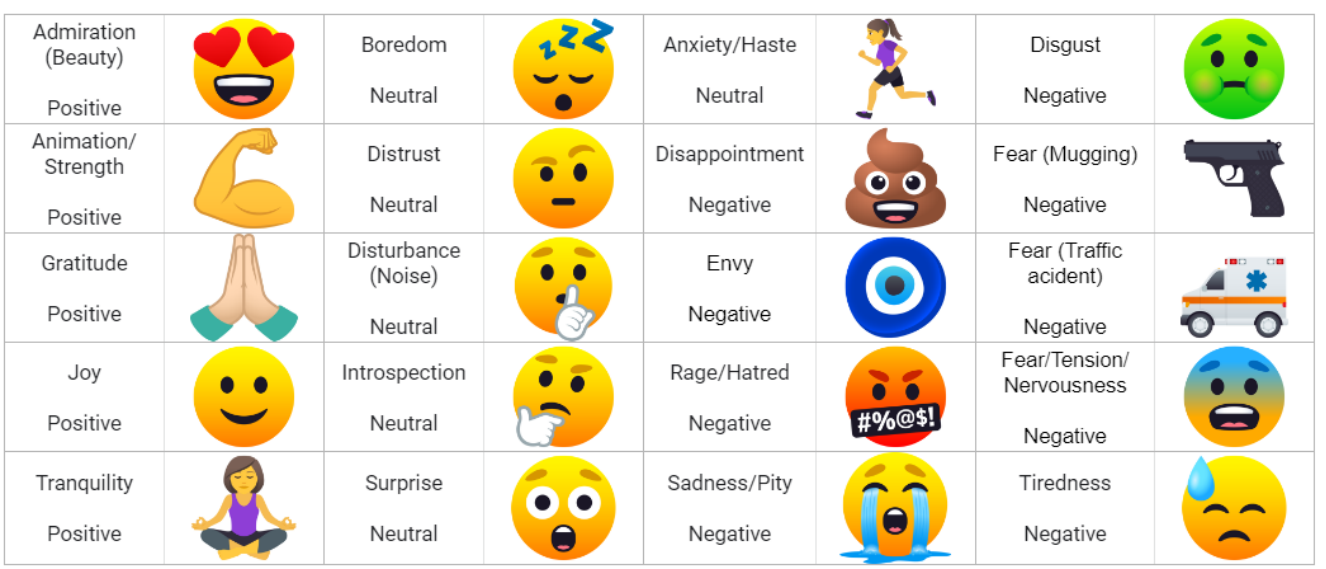

Figure 1. List of emojis semantically analysed for emotional mapping.

Therefore, based on the results, we may conclude that most of the proposed emojis align with the semantics attributed to them within the urban mobility context. Also, it was possible to understand how people interpreted emotions and their synonyms, allowing the creation of a group of emotions associated with a unique emoji. In addition, we concluded that it is essential to differentiate categories of fear, such as an emoji that describes a general fear and others for more specific situations. Finally, considering this research is in progress, we are still analysing the relationship between emotions and the groups surveyed, like gender and transport modes. The list of emojis and associated emotions produced in this phase of the project will be used to develop a collaborative tool for emotional data collection and representation in urban mobility scenarios.

\section{References:}

1. Camara, G. S., Camboim, S. P., Bravo, J. V. M. (2021). Collaborative emotional mapping as a tool for urban mobility planning. Bulletin of Geodetic Sciences. 27(spe): e2021011.

2. Clarke, L. M. (1989). An experimental investigation of the communicative efficiency of point symbols on tourist maps, The Cartographic Journal, 26:2, 105-110, DOI: 10.1179/caj.1989.26.2.105.

3. Churches, O., Nicholls, M., Thiessen, M., Kohler, M., Keage, H. (2014). Emoticons in mind: An event-related potential study, Social Neuroscience, DOI: 10.1080/17470919.2013.873737 
4. Barrett, L.F. (2006). Solving the emotion paradox: categorization and the experience of emotion. Pers. Soc. Psychol. Rev. 10, 20-46.

5. Ekman, P. (1994). Strong evidence for universals in facial expressions: A reply to Russell's mistaken critique. Psychological Bulletin, v. 115, pp. 268-287.

6. Formiga, E. (2012). Símbolos gráficos: métodos de avaliação de compreensão. $1^{\circ}$ Ed. Blucher Editora.

7. Gartner, G. (2012). Openemotionmap.org - Emotional response to space as an additional concept in cartography. XXII ISPRS Congress, Melbourne, Australia. pp. 473-476.

8. Griffin, A. L., McQuoid, J. (2012). At the Intersection of Maps and Emotion: The Challenge of Spatially Representing Experience. Kartographische Nachrichten, v. 6, pp. 291-299.

9. Klettner, S., Huang, H., Schmidt, M., Gartner, G. (2013). Crowdsourcing affective responses to space. Kartographische Nachrichten, v. 63, pp. 66-73.

10. LeDoux, J. (2012). Rethinking the Emotinal Brain. Neuron Perspective, v. 73, pp. 653-676.

11. MacKerron, G., Mourato, S. (2020). Mappiness: natural environments and in-the-moment happiness. In: Handbook on Wellbeing, Happiness and the Environment. Edward Elgar Publishing, pp. 266-282, Ch. 14. DOI. 10.4337/9781788119344.00022.

12. Nold, C. (2009). Introduction: Emotional Cartography, Technologies of the Self. London: Softhook. http://emotionalcartography.net/EmotionalCartographyLow.pdf . Last accessed 14 May 2021

13. Novak, P. K. et al. (2015). Sentiment of emojis. PLoS ONE, v. 10, n. 12, pp.1-22. DOI. 0.1371/journal.pone.0144296.

14. Pánek, J. (2019). Emotional maps: Participatory crowdsourcing of citizens' perceptions of their urban environment. Cartographic Perspectives, v. 2018, n. 91, pp. 17-29. DOI. 10.14714/CP91.1419.

15. Panksepp, J. (2005). Affective consciousness: Core emotional feelings in animals and humans. Science Direct, Consciousness and Cognition, v. 14, pp. 30-80.

16. Turner, E. (1977). Life in LA 1970. Available in: https://mapdesign.icaci.org/2014/12/mapcarte-353365-lifein-los-angeles-by-eugene-turner-1977/. Last accessed 14 May 2021

17. Zeile, P., Resch, B., Loidl, M., Petutschnig, A., Dörrzapf, L. (2016). Urban Emotions and Cycling Experience-enriching traffic planning for cyclists with human sensor data. GI_Forum, v. 1, pp. 204-216. 